Original Research

\title{
Research on the Impact of Environmental Regulations on the Green Innovation Efficiency of Chinese Industrial Enterprises
}

\author{
Yun Yang ${ }^{1,2 *}$, Ying Wang ${ }^{1}$ \\ ${ }^{1}$ College of Economics and Management, Nanjing University of Aeronautics and Astronautics, Nanjing, Jiangsu, China; \\ No. 29 Jiangjun Avenue, Jiangning District, Nanjing,China \\ ${ }^{2}$ School of Physical and Mathematic Sciences, Nanjing Tech University, Nanjing, Jiangsu, China; \\ 30 Puzhu South Road, Jiangbei New District, Nanjing, Jiangsu, China
}

Received: 13 May 2020

Accepted: 27 July 2020

\begin{abstract}
Green innovation efficiency takes environmental and energy factors into consideration. Enhancing green innovation efficiency is a fundamental requirement for China's innovation-driven development. This paper uses the data of industrial enterprises from 30 provinces (cities, districts) in China from 2007 to 2019 and the data envelopment analysis-slack-based measure (DEA-SBM) method to establish a new model for measuring the efficiency of green innovation in industrial enterprises, and compares that efficiency in three major regions of China. In short, the paper examines the relationship between environmental regulations and the green innovation efficiency of industrial enterprises. The research results show that there are significant regional differences in the efficiency of green innovation in Chinese industrial enterprises, and the relevant regions can basically take into account innovation incentives and environmental protection. Industrial enterprises in the eastern region have higher levels of green innovation efficiency, while the central and western regions have lower levels. There is a significant $\mathrm{U}$-shaped relationship between environmental regulations and green innovation efficiency in the whole country and the eastern region; that is, regional green innovation efficiency decreases first and then increases. The environmental regulations in the central and western regions have no significant impact on green innovation efficiency. Relevant research conclusions have important policy implications for setting reasonable forms of environmental regulations to promote the improvement of green innovation efficiency, and then to build a green economic support belt in China.
\end{abstract}

Keywords: DEA-SBM model, environmental regulation, green innovation efficiency, sustainable development

*e-mail: yycp2007@126.com. 


\section{Introduction}

China's economic development has made tremendous progress, and industry has played an irreplaceable role in this. Since 2011, the average added value of industrial production has reached $36.6 \%$ of the GDP [1]. However, China's traditional industrial model is characterized by high levels of energy consumption and pollution. While driving economic growth, it has also caused ecological and environmental issues that cannot be ignored. Taking carbon emissions as an example, the carbon emissions of industrial industries in 2019 reached $73.0 \%$ of China's total [2], so the low-carbon transition of industrial industries has become a key factor affecting the development of the country's low-carbon economy. According to the reports, as of March 2019, China's pollutant emissions approached or exceeded environmental capacity, $80 \%$ of prefecture-level cities failed to meet national air quality secondary standards, and soil and urban water bodies and groundwater were seriously polluted in some areas [3]. Therefore, strengthening environmental regulations has become an important effort for environmental protection in China. Although strict environmental regulations will restrict pollution discharge to a certain extent and alleviate environmental pressure, it could also crowd out R\&D resources due to increased pollution control costs, which will affect the improvement of technological innovation performance. Under such circumstances, as an important factor in achieving the win-win goals of environmental protection and technological progress, green innovation has become an inevitable choice for regions to win a competitive advantage and achieve economic development under the increasingly stringent environmental regulations. Green innovation efficiency evolved from traditional technological innovation efficiency. Because traditional environmental innovation research does not take ecological and environmental factors into account and only pursues high economic output, its research results may be misleading. Faced with current global environmental pollution problems, scholars have gradually incorporated environmental factors into the research framework of corporate technology innovation. Green innovation efficiency has emerged at a historic moment. It is used to characterize the degree of greenness of technological innovation efficiency in a certain region. Green innovation capability is an important driving force for the low-carbon transition of the industrial industry. Environmental regulation is an important means to make up for market failures in the environmental field [4]. The paper studies the relationship between environmental regulation and green innovation efficiency, and the coordinated development of the environment and the economy under institutional and technological innovation. It is of great significance to the development of China's low-carbon economy. Based on the essence of green innovation, this paper extends the goal of green innovation in industrial enterprises, especially adhering to the unified principle of the pursuit of "economic benefits, environmental benefits and social benefits," and comprehensively considers the economic benefits of industrial enterprises in the process of green innovation, and the resource benefit and environmental benefit output that have realized the transformation from traditional to green innovation.

This paper attempts to answer the following questions: What is the current level of green innovation efficiency of Chinese industrial enterprises? How do environmental regulation tools affect the green innovation efficiency of industrial enterprises in different regions of China? Is there a significant difference between environmental regulations and the efficiency of green innovation by industrial companies in different regions? To address these questions, this paper uses panel data from 30 provinces and cities in China from 2007 to 2019, uses the data envelopment analysis-slack-based measure (DEA-SBM) model to measure the green innovation efficiency of China's regional industrial enterprises, and uses a systematic generalized method of moments (GMM) model to test the effect of environmental regulations. This research will help provide useful policy guidance for regions to rely on environmental regulations to promote green innovation and achieve green transformation and upgrading.

\section{Literature Review}

\section{Measurement and Influencing Factors of Green Innovation Efficiency}

At present, research in academia on the efficiency of green innovation is mainly focused on two aspects, efficiency measurement and influencing factors. Nasierowski and Arcelus (2012) used DEA to measure the efficiency of green innovation and compared the measured results in 2005 and 2010 to analyze the innovation input and output in the innovation process [5]. Ren et al. (2014) used the DEA-RAM model to measure the green innovation efficiency of various regions in Shanxi Province [6]. Liu (2017) used the super-SBM method to measure the green innovation efficiency of China's regional innovation system [7]. Gao and Wang (2018) measured the green innovation efficiency of high energy-consuming industries in the Beijing-Tianjin-Hebei region, and based on this, they used a space panel model to analyze regional economic levels, technological innovation environments, openness levels, resource endowments, and enterprise scale [8]. Zhang et al. (2011) explored the impact mechanism of foreign direct investment (FDI) on the efficiency of green innovation [9]. In terms of measurement methods, most studies use the DEA method, especially the DEA-SBM model, to measure China's green innovation efficiency. It is found that green innovation efficiency in each region is on the rise, but the differences between 
regions are obvious. The eastern, central, and western regions have obvious differences, and the efficiency of green innovation decreases in turn [10].

Based on the use of the SBM model to measure China's green innovation efficiency, some scholars have compared it with traditional innovation efficiency that takes economic benefits into account, as well as energy efficiency and the environment based on the traditional DEA-CCR model, which does not take into account the technological innovation of industrial enterprises. A comparative analysis of benefits shows that the innovation efficiency measurement results of the DEA-SBM model are more in line with reality [11]. Another study used the DEA-RAM model to calculate the green innovation efficiency in China as a whole and in different provinces. The research shows that the changes in the efficiency of green innovation transformation have a periodic characteristic, and the transformation efficiency in various provinces shows an uneven development trend from east to west [12]. Niu et al. (2015) used the improved four-stage DEA-SBM method to evaluate the green innovation efficiency of Chinese industrial enterprises [13]. Wu et al. (2016) used the network SBM model to measure green innovation efficiency and the efficiency values of its three sub-stages, and compared and analyzed the coordinated development of the sub-stages [14]. Based on evaluations of China's green innovation efficiency, some scholars have analyzed its convergence and influencing factors [15], or its spatial spillover effect on regional high-tech industries [17]. According to Han (2012), foreign investment and structural adjustment have significantly promoted the improvement of China's green innovation efficiency; however, environmental regulations and technology markets have not shown a significant positive effect on its growth [17].

\section{Relationship between Environmental Regulation and Green Innovation Efficiency}

Environmental regulation is of great significance to the improvement of urban green innovation efficiency. Porter and van der Linde (1995) pointed out that strict but appropriate environmental regulations can promote innovation to a certain extent, and the benefits that are generated can be sufficient to offset the costs incurred by enterprises, thereby allowing them to gain a competitive advantage. This is known as the Porter hypothesis, which provides a theoretical basis for studying the impact of environmental regulations on the efficiency of green innovation [18]. Scholars believe that enterprises will not take the initiative to assume environmental responsibility due to their own development considerations. In the absence of environmental regulations, they will not take the initiative to reduce carbon emissions and protect the environment [19]. Environmental regulation has a significant impact on the efficiency of green innovation; the relationship between the two is not a simple linear one, and it has complex impact and action mechanisms. Hui and Guo (2018) found through industry research that environmental regulation has a threshold effect on the role of green innovation efficiency [20]. Yang et al. (2018) studied the spatiotemporal evolution of the Yangtze River Economic Belt and showed that environmental regulation has a U-shaped effect on green innovation efficiency and a significant inflection point effect [21]. However, with the deepening of our understanding of environmental regulations, some scholars have incorporated them in the input-output index system and made them an endogenous factor for efficiency evaluation. Because China's statistical yearbook provides more detailed data on pollution reduction expenditures, the method of measuring the intensity of environmental regulations with pollution treatment inputs is widely used in China's green innovation efficiency research [22]. As a kind of capital investment, pollution treatment inputs as one of the input indicators is included in the efficiency evaluation index system. For example, Xiang and Lin (2018) used the twostage network DEA-Malmquist model to evaluate the total factor productivity of the industrial environment using pollution control inputs as input indicators [23]. $\mathrm{Li}$ et al. (2018) took the intensity of environmental regulation as an input in the stage of technological transformation and included it in the evaluation index system of technological innovation efficiency [24]. Horbach (2015) used German-related panel data as a research sample set and a discrete selection model to test the impact of formal environmental regulations on green innovation. Empirical evidence shows that formal environmental regulation tools can trigger the green innovation effect and constitute an important driving force for green innovation [25]. Chen (2011) used an analysis model of formal environmental regulatory policy tools based on tradable emission permits and introduced an innovative mechanism to investigate the impact of these tools on small and medium-sized enterprises (SMEs). The results show that tradable emission permits and subsidies are a combined formal environmental regulatory tool that can stimulate green innovation in SMEs with low regulatory cost [26]. You and Wang (2016) used mathematical models to deduce formal environmental regulations to promote $R \& D$ preference for green technology research and further empirical tests using the GMM method. It was found that relying on formal environmental regulations alone could not promote green technology innovation; R\&D must play an intermediary role [27].

To sum up, there are few studies on the relationship between environmental regulations and green innovation efficiency at home and abroad. Most of the studies are based on province- or prefecture-level data, and no consistent conclusions have been reached. Moreover, the existing literature generally does not consider undesired output. Based on the urgency of carbon dioxide emission reduction in China, this paper uses pollution emissions as the undesired output 
to study the impact of environmental regulations on the efficiency of green innovation. Based on this, this paper takes 30 provinces (cities, districts) in mainland China from 2007 to 2019 as the sample for analysis (Tibet is omitted due to the lack of relevant indicator data), considering the essence of green innovation and the innovation process The undesirable outputs of the middle part provides an evaluation of the innovation efficiency of China's green regions, based on which we examine the impact of environmental regulations on green innovation and propose relevant policy recommendations.

\section{Methods}

\section{DEA-SBM Model}

Traditional DEA models assume that all outputs are ideal. However, some output indicators of the actual production process do not have this characteristic. Reducing output is conducive to improving its efficiency, and such output is called non-ideal output. The traditional method is to treat non-ideal output as input, and another method is to treat the reciprocal as the ideal output, but these two processing methods are contrary to the actual production process. In addition, the traditional DEA model is based on the idea of the Farrell efficiency measure, which belongs to the measurement theory of radial and linear piecewise forms. The idea of this measurement is mainly disposability, ensuring the convexity of the production possibility boundary (it will not bend), but when there is congestion or slack in the factor (when there is nonzero slack in the input or output), the efficiency of the decision unit will be overestimated. In order to overcome the shortcomings of the existing traditional DEA model, this paper uses a new type of DEA-SBM model proposed by Tone. This model directly puts relaxation variables into the objective function, which not only solves the problem of input-output relaxation, but also solves non-efficiency evaluation in the presence of expected output [28].

Suppose there are $\mathrm{n}$ decision-making units, each of which has three input-output vectors: inputs, expected outputs, and undesired outputs. The three vectors are expressed as $\mathrm{x} \in R^{m}, y^{g} \in R^{S_{1}}, y^{b} \in R^{S_{2}}, \mathrm{X}, Y^{g}, Y^{b}$ can be defined as follows:

$$
\begin{aligned}
& \mathrm{X}=\left[x_{1}, \cdots, x_{n}\right] \in R^{m} \\
& \mathrm{Y}^{g}=\left[y_{1 X>0}^{g}, \cdots, y_{n}^{g}\right] \in R^{S_{1}} \\
& \mathrm{Y}^{b}=\left[y_{1}^{b}, \cdots, y_{n}^{b}\right] \in R^{s_{2}}
\end{aligned}
$$

Among them, $Y^{g}>0, Y^{b}>0$, the set of production possibilities $\mathrm{P}$ under constant scale returns can be defined as:

$$
\mathrm{P}=\left\{\frac{\left(x, y^{g}, y^{b}\right)}{x} \geq X \lambda, y^{g} \leq Y^{g} \lambda, y^{b} \geq Y^{b} \lambda, \lambda \geq 0\right\}
$$

The non-radial non-angle DEA-SBM directional distance function model considering the undesired output is:

$$
\begin{gathered}
\rho^{*}=\min \frac{1-\frac{1}{m} \sum_{i=1}^{m} \frac{s_{i}^{-}}{x_{i 0}}}{1+\frac{1}{s_{1}+s_{2}}\left[\sum_{r=1}^{s_{1}} \frac{s_{r}^{g}}{y_{r 0}^{g}}+\sum_{r=1}^{s_{2}} \frac{s_{r}^{b}}{y_{r 0}^{b}}\right]} \\
\text { s.t. } x_{0}=X \lambda+s^{-} \\
y_{0}^{g}=Y^{g} \lambda-s^{g} \\
y_{0}=Y^{b} \lambda+s^{b} \\
s^{-} \geq 0, s^{g} \geq 0, s^{b} \geq 0, \lambda \geq 0
\end{gathered}
$$

...where $s$ represents the slack of various inputs and expected and undesired outputs, and $\lambda$ is the weight vector. The objective function $\rho^{*}$ strictly decreases with respect to $\mathrm{s}^{-}, \mathrm{s}^{\mathrm{g}}$, and $\mathrm{s}^{\mathrm{b}}$, and $0<\rho^{*}<1$. For a specific unit to be evaluated, it is efficient if and only if $\rho^{*}=1$, that is, $\mathrm{s}^{-}=0, \mathrm{~s}^{\mathrm{g}}=0$, and $\mathrm{s}^{\mathrm{b}}=0 . \rho^{*}<1$ indicates that the unit being evaluated is invalid and the input and output need to be improved. Equation (5) is a nonlinear program that can be solved by Charnes's transformation method.

\section{System GMM Model}

Hansen (1999) systematically described generalized method of moments (GMM) [29]. Since the generalized moment estimation method allows heteroscedasticity and sequence correlation for random error terms, the obtained parameter estimates are more practical than other parameter estimation methods. When performing empirical analysis of panel data, the GMM method is widely used to handle the existence of endogenous problems. The method also allows us to select the lagging number, including the dependent and independent variables as instrumental variables, to solve the problem of inconsistency. The GMM method is also more flexible than the general instrumental variable method. We chose the constant term and the lag period of the dependent and independent variables from 1 to 2 as the set of instrumental variables. The model is constructed as follows:

$$
\mathrm{y}_{\mathrm{it}}=\alpha y_{i t-1}+\beta X_{i t}+\mu_{i}+\varepsilon_{i t}
$$

...where $\mathrm{y}_{\mathrm{it}}$ is the explanatory variable, $\mathrm{X}_{\mathrm{it}}$ is the explanatory variable, $\mu_{\mathrm{it}}$ is the regional effect, and $\varepsilon_{\mathrm{t}}$ is the residual of the model. In order to solve the possible individual fixed effects, Arellano-Bond used the GMM method to perform first-order difference processing on the formula and obtained: 


$$
\Delta y_{i t}=\alpha \Delta y_{i t-1}+\beta \Delta X_{i t}+\Delta \mathcal{E}_{i t}
$$

It can be seen from the formula that the model after differential processing solves the individual fixed effects. Although the system GMM method does not need to consider the stability of the data, there is a two-way causal relationship between the variables, also called endogeneity. In order to solve this endogeneity, this paper uses the Sargan and Arellano-Bond tests to verify the model and variables.

\section{Results}

\section{Measurement of Regional Green Innovation Efficiency in China}

\section{Variable Selection}

(1) Input indicators. For green innovation investment indicators, we mainly focus on basic core resource elements, specifically from human and material resources.

Financial resources are considered in three aspects. Traditional research generally tends to use two indicators, R\&D personnel and funding investment, to measure innovation investment. However, this paper considers that these two indicators are more suitable for $\mathrm{R} \& \mathrm{D}$ or independent innovation investment, because the two innovation models mainly involve the production of knowledge and have a higher requirement for the quality of input resources. However, the research object of this paper is broader in meaning and more general in technological innovation. Therefore, we selected as input scientific and technological personnel and internal expenditure of scientific and technological activities as human resources and financial resources (funds) for green innovation of enterprises, so as to avoid unrealistic research results. Regarding the level of capital input, most existing studies use the perpetual inventory method to calculate the capital stock to measure, but that method requires a preset capital input-output ratio, and the selection of this ratio is subjective. The capital investment used by an enterprise for a certain period of time is the total assets owned by the enterprise during that period, so we chose the total asset value (100 million yuan) of industrial enterprises above a designated size to represent the level of capital investment of industrial enterprises in a period. Energy input is represented by the consumption of industrial fossil energy in end consumption.

(2) Innovation output indicators. According to the connotation of green innovation, it must not only improve the ecological benefits of the natural environment, but also obtain economic benefits of potential profits and social benefits of improving the quality of human life. This paper considers the output indicators of corporate green innovation as "economic growth, resource conservation, and environmental protection," including economic benefits, resource benefits, and environmental benefits output. The patent is the main output of the green innovation knowledge production process. It is the core and the most economically valuable part of a company's technology assets. Patents include the number of patent applications and grants. Relatively speaking, because the number of patent grants is affected and restricted by the government's patent examination agency, the uncertain factors are relatively large. Such uncertainty is likely to cause abnormal changes in the number of patent grants. Therefore, the number of patent applications can better reflect the true level of innovation. In addition, patents include three types of inventions, utility models, and designs, and different types of patents have significant differences in terms of degree of innovation, technical importance, economic value, etc. It may not be appropriate to use the total number of patents as the innovation output. Among the patents, invention patents have strong novelty, high technical content, good market application prospects, and high market recognition. Therefore, the number of invention patent applications was selected as an indicator to measure the potential market benefits and value realization of green innovation. However, because patents cannot accurately reflect the transformation ability and market value of innovation results, using them to measure the economic benefits has major limitations. Therefore, it is necessary to choose supplementary indicators to measure the economic benefits of green innovation. This paper adopts an index based on market benefits, new product sales revenue, as an evaluation index to measure the economic benefits green innovation brings to enterprises.

The role of technological innovation in promoting social development has become increasingly important. As the main component of the national economy, industrial enterprises have gradually paid attention to the comprehensive benefits their innovation brings. Industrial enterprises promote green innovation, and its ideal effect is the ability to produce economic, environmental, and social benefits in three aspects, so as to truly improve the competitiveness of the industry and comply with the national innovation strategy. At this stage, the environmental and social benefits brought by technological innovation should be mainly reflected in the contributions made by resource conservation (resource benefits) and the reduction of environmental pollution, and the creation of an environmentally friendly society (environmental benefits). This paper studies the green innovation efficiency of industrial enterprises. In terms of output, it is necessary to consider the discharge of environmental pollutants. We selected three undesirable outputs: the total amount of industrial wastewater discharge, the industrial sulfur dioxide emissions, and the industrial solid waste emissions in each region. Output indicators were used to measure the environmental benefits brought by the green innovation of industrial enterprises. The energy 
Table 1. Index system.

\begin{tabular}{|c|c|c|}
\hline Index & Index classification & Index composition \\
\hline \multirow{4}{*}{ Input index } & \multirow{2}{*}{ Labor } & Investment in scientific and technological activities \\
\hline & & Internal expenditure for scientific and technological activities \\
\hline & Capital & Total assets of industrial enterprises above designated size \\
\hline & Energy & Total energy consumption \\
\hline \multirow{5}{*}{$\begin{array}{l}\text { Output } \\
\text { indicators }\end{array}$} & \multirow{2}{*}{ Expected output } & Invention patent applications \\
\hline & & New product sales revenue \\
\hline & \multirow{3}{*}{ Undesirable output } & Industrial wastewater discharge emissions \\
\hline & & Industrial sulfur dioxide emissions \\
\hline & & Industrial solid waste discharge emissions \\
\hline
\end{tabular}

utilization level can reflect the promotion of economic operation quality and efficiency by innovation. This paper uses the energy utilization level to measure the energy efficiency brought by green innovation, and specifically selects the comprehensive energy consumption output rate of industrial enterprises as an indicator. The index system is constructed as shown in Table 1.

\section{Results of Green Innovation Efficiency}

Using DEAP 2.1 software, the determined input indicators and output indicators were substituted into the model, and the calculation results are shown in Table 2.

As can be seen from the table, the eastern region had the highest green innovation efficiency of industrial enterprises from 2007 to 2019, with an average value of 0.738 . The average value in the eastern provinces was mostly above 0.7 and in the central region was 0.451 . During the sample period, the overall trend showed a slow increase, and gradually stabilized above 0.5 from the initial 0.406 . The change trend was the same as that of the national value. The lowest value is in the western region, at around 0.4 , but it can also be found that the values in the central and western regions are very close. This is inconsistent with previous research results, which may be because most previous studies did not analyze environmental factors as output, leading to deviations in the measurement results.

Impact of Environmental Regulations on the Efficiency of Regional Green Innovation

\section{Variable Selection}

\section{(1) Explained variable}

The explained variable is the green innovation efficiency of China's regional industrial enterprises including environmental constraints calculated using the data envelopment analysis method above, denoted as GE.
(2) Explanatory variables

Environmental regulatory strength (ERS). Summarizing previous research, domestic and foreign scholars measure environmental regulation mainly in the following ways: the first is to use per capita GDP or per capita income level as a proxy variable for environmental regulation [30-31]; the second is to use the emissions of a certain pollutant or emission intensity as a proxy variable for environmental regulation $[32,33]$; the third is to measure the intensity of environmental regulation by the cost or expense of environmental pollution control [34-35]; and the fourth is to use the comprehensive index method to construct an index system to measure the intensity of pollution emissions, and take it as a substitute indicator of environmental regulation [36]. Because the indicators used in the first three methods are relatively solitary, they cannot accurately reflect environmental regulations. In general, the higher the intensity of pollution emissions in a region, the stricter its environmental regulation policies. Based on this, this paper adopts the fourth method to construct a comprehensive measurement system. The indicators of industrial wastewater exhaust gas and solid waste emissions in various regions are selected to measure the intensity of pollution discharge as a substitute indicator for environmental regulations. The specific treatment is as follows: Linearly normalize each indicator:

$$
U E_{i j}=\frac{E_{i j}-\min \left(E_{j}\right)}{\max \left(E_{j}-\min E_{j}\right)}
$$

...where $E_{i j}$ is the emission amount of type $j$ pollutants in area $i, \max \left(E_{j}\right)$ and $\min \left(E_{j}\right)$ are the maximum and minimum values of type $\mathrm{j}$ pollutant emissions in all areas, and $\mathrm{UE}_{\mathrm{ij}}$ is the standardization of the indicator value. Calculate the adjustment coefficient $\mathrm{Wj}$ of each indicator and assign weights to the pollutant indicators in each region. Due to large differences in the proportions of industrial "three waste" pollutants in different regions, the use of adjustment 
Table 2. Measurement results.

\begin{tabular}{|c|c|c|c|c|c|c|c|c|c|c|c|c|c|c|c|}
\hline & Region & 2007 & 2008 & 2009 & 2010 & 2011 & 2012 & 2013 & 2014 & 2015 & 2016 & 2017 & 2018 & 2019 & Mean \\
\hline \multirow{11}{*}{ Eastern } & Beijing & 0.833 & 0.826 & 0.857 & 0.881 & 0.914 & 0.936 & 0.966 & 0.988 & 1.004 & 1.053 & 1.098 & 1.127 & 1.148 & 0.972 \\
\hline & Tianjin & 0.622 & 0.625 & 0.629 & 0.612 & 0.625 & 0.637 & 0.646 & 0.659 & 0.675 & 0.687 & 0.695 & 0.711 & 0.723 & 0.657 \\
\hline & Hebei & 0.359 & 0.362 & 0.369 & 0.374 & 0.387 & 0.408 & 0.426 & 0.438 & 0.446 & 0.467 & 0.479 & 0.487 & 0.496 & 0.423 \\
\hline & Liaoning & 0.373 & 0.381 & 0.386 & 0.371 & 0.385 & 0.396 & 0.402 & 0.421 & 0.435 & 0.461 & 0.477 & 0.487 & 0.511 & 0.422 \\
\hline & Shanghai & 0.822 & 0.825 & 0.835 & 0.839 & 0.846 & 0.855 & 0.867 & 0.875 & 0.889 & 0.911 & 0.932 & 0.953 & 0.978 & 0.879 \\
\hline & Jiangsu & 0.744 & 0.748 & 0.753 & 0.767 & 0.779 & 0.794 & 0.799 & 0.813 & 0.827 & 0.838 & 0.845 & 0.872 & 0.889 & 0.805 \\
\hline & Zhejiang & 0.721 & 0.726 & 0.733 & 0.738 & 0.743 & 0.749 & 0.755 & 0.765 & 0.776 & 0.787 & 0.799 & 0.806 & 0.825 & 0.763 \\
\hline & Fujian & 0.803 & 0.810 & 0.814 & 0.821 & 0.834 & 0.846 & 0.858 & 0.868 & 0.879 & 0.891 & 0.904 & 0.921 & 0.933 & 0.860 \\
\hline & Shandong & 0.735 & 0.741 & 0.745 & 0.751 & 0.754 & 0.759 & 0.766 & 0.776 & 0.785 & 0.791 & 0.809 & 0.823 & 0.851 & 0.776 \\
\hline & Guangdong & 0.713 & 0.719 & 0.724 & 0.723 & 0.738 & 0.749 & 0.756 & 0.764 & 0.773 & 0.783 & 0.797 & 0.806 & 0.823 & 0.759 \\
\hline & Hainan & 0.755 & 0.759 & 0.766 & 0.771 & 0.778 & 0.784 & 0.791 & 0.803 & 0.819 & 0.832 & 0.847 & 0.861 & 0.877 & 0.803 \\
\hline \multicolumn{2}{|c|}{ Eastern mean } & 0.680 & 0.684 & 0.692 & 0.695 & 0.708 & 0.719 & 0.730 & 0.743 & 0.755 & 0.773 & 0.789 & 0.805 & 0.823 & 0.738 \\
\hline \multirow{8}{*}{ Central } & Shanxi & 0.313 & 0.316 & 0.318 & 0.323 & 0.326 & 0.336 & 0.343 & 0.356 & 0.367 & 0.372 & 0.385 & 0.393 & 0.412 & 0.351 \\
\hline & Jilin & 0.343 & 0.346 & 0.345 & 0.353 & 0.363 & 0.372 & 0.379 & 0.388 & 0.391 & 0.399 & 0.408 & 0.416 & 0.435 & 0.380 \\
\hline & Heilongjiang & 0.511 & 0.514 & 0.517 & 0.525 & 0.531 & 0.539 & 0.547 & 0.558 & 0.569 & 0.581 & 0.599 & 0.609 & 0.634 & 0.556 \\
\hline & Anhui & 0.312 & 0.317 & 0.319 & 0.326 & 0.335 & 0.336 & 0.346 & 0.359 & 0.368 & 0.379 & 0.388 & 0.398 & 0.412 & 0.353 \\
\hline & Jiangxi & 0.352 & 0.355 & 0.363 & 0.366 & 0.376 & 0.388 & 0.399 & 0.417 & 0.419 & 0.427 & 0.451 & 0.476 & 0.489 & 0.406 \\
\hline & Henan & 0.334 & 0.339 & 0.343 & 0.349 & 0.356 & 0.364 & 0.377 & 0.389 & 0.398 & 0.403 & 0.428 & 0.446 & 0.463 & 0.384 \\
\hline & Hubei & 0.546 & 0.549 & 0.558 & 0.566 & 0.576 & 0.589 & 0.593 & 0.608 & 0.617 & 0.631 & 0.646 & 0.665 & 0.687 & 0.602 \\
\hline & Hunan & 0.533 & 0.535 & 0.539 & 0.547 & 0.554 & 0.568 & 0.577 & 0.579 & 0.586 & 0.593 & 0.599 & 0.608 & 0.611 & 0.571 \\
\hline \multicolumn{2}{|c|}{ Central mean } & 0.406 & 0.409 & 0.413 & 0.419 & 0.427 & 0.437 & 0.445 & 0.457 & 0.464 & 0.473 & 0.488 & 0.501 & 0.518 & 0.451 \\
\hline \multirow{11}{*}{ Western } & Neimenggu & 0.256 & 0.262 & 0.269 & 0.275 & 0.286 & 0.297 & 0.308 & 0.319 & 0.324 & 0.336 & 0.344 & 0.357 & 0.308 & 0.340 \\
\hline & Guangxi & 0.345 & 0.348 & 0.354 & 0.361 & 0.368 & 0.375 & 0.378 & 0.386 & 0.398 & 0.412 & 0.431 & 0.449 & 0.390 & 0.387 \\
\hline & Chongqing & 0.541 & 0.544 & 0.548 & 0.552 & 0.559 & 0.566 & 0.573 & 0.579 & 0.589 & 0.598 & 0.609 & 0.622 & 0.578 & 0.540 \\
\hline & Sichuan & 0.345 & 0.351 & 0.358 & 0.362 & 0.369 & 0.375 & 0.382 & 0.389 & 0.397 & 0.407 & 0.411 & 0.417 & 0.384 & 0.334 \\
\hline & Guizhou & 0.233 & 0.237 & 0.239 & 0.241 & 0.249 & 0.258 & 0.265 & 0.271 & 0.285 & 0.295 & 0.305 & 0.317 & 0.271 & 0.274 \\
\hline & Yunnan & 0.311 & 0.314 & 0.322 & 0.331 & 0.337 & 0.341 & 0.351 & 0.364 & 0.369 & 0.377 & 0.399 & 0.418 & 0.359 & 0.374 \\
\hline & Shaanxi & 0.336 & 0.342 & 0.348 & 0.356 & 0.359 & 0.368 & 0.379 & 0.399 & 0.407 & 0.414 & 0.428 & 0.446 & 0.389 & 0.386 \\
\hline & Gansu & 0.255 & 0.262 & 0.277 & 0.279 & 0.283 & 0.296 & 0.308 & 0.319 & 0.328 & 0.339 & 0.344 & 0.357 & 0.309 & 0.370 \\
\hline & Qinghai & 0.552 & 0.558 & 0.564 & 0.571 & 0.578 & 0.588 & 0.597 & 0.613 & 0.623 & 0.638 & 0.648 & 0.664 & 0.605 & 0.609 \\
\hline & Ningxia & 0.533 & 0.537 & 0.544 & 0.555 & 0.559 & 0.566 & 0.578 & 0.598 & 0.608 & 0.623 & 0.633 & 0.648 & 0.588 & 0.568 \\
\hline & Xinjiang & 0.347 & 0.354 & 0.363 & 0.368 & 0.372 & 0.376 & 0.383 & 0.389 & 0.394 & 0.405 & 0.419 & 0.429 & 0.389 & 0.395 \\
\hline \multicolumn{2}{|c|}{ Western mean } & 0.369 & 0.374 & 0.381 & 0.386 & 0.393 & 0.401 & 0.409 & 0.421 & 0.429 & 0.440 & 0.452 & 0.466 & 0.480 & 0.415 \\
\hline \multicolumn{2}{|c|}{ National mean } & 0.493 & 0.497 & 0.503 & 0.508 & 0.517 & 0.527 & 0.537 & 0.548 & 0.558 & 0.571 & 0.585 & 0.600 & 0.616 & 0.543 \\
\hline
\end{tabular}

coefficients can approximately reflect such differences. The weight calculation method is as follows:

$$
W_{j}=\frac{E_{j} / \sum E_{j}}{Q_{j} / \sum Q_{j}}
$$

That is, $W_{j}$ is the proportion of pollutant j's emissions in a region to total emissions and the proportion of the region's GDP to the GDP of all regions. Through the standardized values and weights of individual pollutant index values, the environmental regulations and total environmental regulation intensity of each index are calculated, respectively: 
Table 3. Regression results.

\begin{tabular}{|c|c|c|c|c|}
\hline & National & Eastern & Central & Western \\
\hline \multirow{2}{*}{$\alpha$} & $0.312 * *$ & \multirow{2}{*}{ NA } & $1.221^{*}$ & $1.098 *$ \\
\hline & $(0.0010)$ & & $(0.0001)$ & $(0.0002)$ \\
\hline \multirow{2}{*}{$\operatorname{lnERS}$} & $-0.213 * * *$ & $-0.247 * * *$ & $-0.132 * * *$ & $-0.111 * * *$ \\
\hline & $(0.0000)$ & $(0.0000)$ & $(0.00003)$ & $(0.0001)$ \\
\hline \multirow{2}{*}{$(\mathrm{LnERS})^{2}$} & $0.325 * * *$ & $0.039 * * *$ & 0.021 & 0.018 \\
\hline & $(0.0000)$ & $(0.0001)$ & $(0.1210)$ & $(0.3313)$ \\
\hline \multirow{2}{*}{ LnGDP } & -0.121 & -0.091 & -0.035 & $0.023^{* * *}$ \\
\hline & $(0.1650)$ & $(0.473)$ & $(0.451)$ & $(0.0001)$ \\
\hline \multirow{2}{*}{ LnFDI } & $0.063 * * *$ & 0.051 & $0.363^{*}$ & 0.022 \\
\hline & $(0.0001)$ & $(0.471)$ & $(0.082)$ & $(0.3521)$ \\
\hline \multirow{2}{*}{ LnHUM } & $0.779 * * *$ & $0.9181 * * *$ & 0.027 & $0.535^{* * *}$ \\
\hline & $(0.0000)$ & $(0.0001)$ & $(0.2501)$ & $(0.000)$ \\
\hline \multirow{2}{*}{ LnGS } & 0.012 & 0.021 & 0.132 & 0.1732 \\
\hline & 0.251 & $(0.182)$ & $(0.332)$ & $(0.2432)$ \\
\hline Sargan & \multicolumn{4}{|c|}{0.032} \\
\hline Wald & \multicolumn{4}{|c|}{0} \\
\hline
\end{tabular}

$$
\begin{gathered}
S_{i}=\frac{1}{n} \sum_{j=1}^{n} W_{j} \cdot U E_{i j} \\
E R S=\sum_{i=1}^{p} S_{i}
\end{gathered}
$$

Economic development level (GDP). Enterprises need a lot of financial and human resources for green production, and because of agglomeration effects and profitability, many production factors are gathered in economically developed regions, so that regional companies are more conscious and capable of green innovation activities. This study uses the logarithm of actual per capita GDP to measure.

Foreign direct investment (FDI). FDI can generate technology diffusion. According to technology spillover effects, foreign-funded enterprises actively carry out various innovation activities in China. On the one hand, improving the efficiency of the use of innovation resources in China improves the industrial innovation environment, in terms of enthusiasm for the activity. However, the influx of foreign businessmen has also brought about the migration of industries. Most Chinese companies have inherited high-polluting and highenergy-consuming industries from abroad, which have hindered the improvement of green innovation efficiency [37-38]. Whether foreign investment can effectively improve the innovation efficiency of the host country has always been the focus of discussion in academic circles, but there is no unified conclusion. Therefore, this paper includes foreign direct investment in the model for testing. Since the unit of FDI is denominated in US dollars, we use the current exchange rate to convert total foreign direct investment in various regions into RMB units, and calculate it as the constant price in 2007.

Human capital (HUM). The investment in and accumulation of human capital is an important basis for maintaining the continuous growth of green innovation efficiency. The input of scientific and technological personnel is the main driving force for technological innovation and progress. The development of technology can change the intensity and direction of pollution emissions. Therefore, the average annual number of employees in high-tech industries is used as a control variable in the threshold model to measure labor input.

Government support (GS). The government's financial support can increase investment in innovation resources, make up for the lack of corporate innovation research and development funds, and increase investment in innovation resources. On the other hand, it could have a "crowding effect" on a company's own R\&D funds, and improper use of government $R \& D$ funds could also reduce the efficiency of green innovation. The influence of government support on the efficiency of green innovation cannot be determined. Therefore, we use government support as a factor influencing inefficient green innovation areas for regression analysis. Due to government policy support and infrastructure construction, specific data cannot be 
used for measurement. This paper uses the proportion of regional government technology investment in GDP as the impact of government support on the efficiency of green innovation [39-40].

\section{Regression Results and Analysis Based on System GMM Model}

This paper evaluates the existing literature, considering the availability of data, and uses the intensity of environmental regulations (ERS), the level of economic development (GDP), foreign direct investment (FDI), human capital (HUM), and government support (GS) as explanations. Green innovation efficiency (GE) is used as the explanatory variable, the sampling interval is 2007-2019, and the following regression equation is established:

$$
\begin{gathered}
\ln G E=\alpha+\beta_{1} \ln E R S_{i t}+\beta_{2} \ln E R S_{i t}{ }^{2}+\beta_{2} \ln G D P_{i t}+ \\
\beta_{3} \ln F D I_{i t}+\beta_{4} \ln H U M_{i t}+\beta_{5} \ln G S_{i t}+\mu
\end{gathered}
$$

...where $\mathrm{i}$ is the region, $\mathrm{t}$ is the time, GE is green innovation efficiency, and ERS is the level of environmental regulation. At the same time, in order to verify whether there is a nonlinear relationship between environmental regulation and green innovation efficiency, the second term of ERS is included as an explanation in the model variable. $\mu$ is a random error term and is a coefficient for explaining variable $\mathrm{x}$. Control variables include the levels of regional economic development, foreign direct investment, human capital, and government support.

We used Stata 12.0 software and the systems generalized moment's estimation method to estimate the model. The results are shown in Table 3.

It can be seen in Table 1 that among the overall national regression results, the coefficients of the primary terms of environmental regulation variables are negative and the coefficients of the quadratic terms are positive during the period under review, all of which are significant at the $1 \%$ level. This shows that the impact of environmental regulation on the efficiency of regional green innovation gradually changes with increased intensity. With the gradual increase of environmental regulation intensity, green innovation efficiency has a U-shaped characteristic that first decreases and then increases. This may be because early in the implementation of environmental regulatory policies, the intensity of regulation was low, regions did not have enough incentives to adopt green innovation for the purpose of conserving energy and reducing emissions, and it affected innovation institutions due to the increased cost of controlling environmental pollution. R\&D funds produced a "crowding effect," which reduced the efficiency of regional green innovation. However, as the intensity of regulations continued to increase, the cost of controlling environmental pollution in various regions continued to increase, making it necessary to increase the technological level of pollution control by increasing innovation investment. In the process of innovation, innovation resources are then tilted toward the research and development of green products, in order to achieve the goal of reducing pollutant emissions and maintaining profitability from the source.

According to the estimation results by region, the estimated coefficient of the primary term of environmental regulation in the eastern region is significantly negative, and the estimated coefficient of the quadratic term is significantly positive. Environmental regulation and green innovation efficiency still conform to the U-shaped relationship, but the estimation results are not significant. For a long time, the development of the eastern region has been ahead of that of the central and western regions. It has a relatively mature scientific and technological innovation system and model, and its residents have a stronger sense of environmental protection and a stronger preference for green products. The motivation is also stronger, which makes the impact of environmental regulations more obvious. Because the foundation of green innovation activities in the central and western regions is relatively weak, the green innovation model and resource allocation mechanism are not very mature, so the impact of environmental regulations is not obvious. This is consistent with the results of most scholars. For example, scholars Gao and Wang (2018) found that environmental regulations have a significant positive effect on areas where the efficiency of green technology innovation is generally ( 0.5 to 0.8$)$, but has low and high efficiency. The two types of areas have a negative impact, that is, different impact results in different areas [41].

From the estimation results of the control variables, the regression coefficient of the level of regional economic development (GDP) in the country is not significant, indicating that China's extensive economic development model, characterized by the pure pursuit of an economic growth rate, large consumption of resources, and pollution of the environment, cannot promote improvement of innovation efficiency. In terms of different regions, the estimation results of the eastern and central regions support this conclusion, but the regression coefficient of the economic development level in the western region is significantly positive. The reason may be that economic development of this region mainly depends on industrial transfer and technology of the central and eastern regions. Overflow as well as introduced and adopted advanced green innovation technology led to a significant positive correlation between the level of economic development in the western region and green technology innovation,this is consistent with the research of most scholars [42].

In terms of foreign direct investment (FDI), foreign investment across the country and central regions has a significant positive effect on green innovation efficiency, while the estimated coefficients in the eastern 
and western regions are not significant. This may be due to the large differences in foreign investment in terms of scale and technological content, and even the same type of foreign investment will have different effects due to the inadequate conditions of the inflow region. After years of being built up in the eastern region, green innovation capabilities have made great progress, and the gap with foreign countries has gradually narrowed and China is catching up, weakening its dependence on foreign technology to a certain extent, so that the impact of foreign investment is no longer obvious. The central region initially established a relatively complete green innovation mechanism in the process of undertaking industrial transfer in the east. Foreign capital inflows have brought advanced management experience and technology and promoted the improvement of green innovation efficiency in the central region. The western region has a weak foundation for green innovation, and its own absorptive capacity is limited. As a result, the promotion effect of foreign capital on green innovation has not yet been seen. This is different from the research of other scholars.For example, scholars Xiao and $\mathrm{Wu}$ (2019) used data from 536 industrial enterprises above designated size in 30 provinces to empirically study the impact of FDI and environmental regulation policies on the efficiency of regional green innovation. The research found that FDI has a significant effect on regional green innovation. However, the scholar also confirmed that different regions may have different results [43]. The main reason for this difference may be different samples. This article analyzes the impact of the three specific regions to reflect the problem more comprehensively. Other scholars have reached the same conclusion [44-45].

Human capital (HUM) has a significant positive effect on promoting green innovation in the country and the eastern region, but it has no significant impact on the central region and a significant promoting effect on the western region. High levels of talent and perfect infrastructure are the basic supports for green innovation activities in various regions. The central region needs to improve its personnel training and talent attraction mechanism as soon as possible. The western region needs to focus on strengthening infrastructure construction to create its basic support for green innovation as soon as possible. Jiang et al. (2019) also believe that the level of human capital and human capital investment have a significant impact on the innovation performance of my country's manufacturing green innovation system, and the impact of human capital level is more significant.

Government support (GS): There is a positive correlation between the green innovation behavior of enterprises and innovation efficiency and government support, but the effect is not significant, indicating that government support has a limited effect on improving green innovation efficiency. The government wants to provide various types of capital subsidies for resourcebased enterprises mainly because government subsidies can effectively help enterprises to develop new technologies, and at the same time, they can reduce a company's research and development costs. However, government support is a double-edged sword, as there have also been some counter-effects in making up for the shortage of corporate funds. The central and western regions have weak infrastructure, and government investment should be processed and absorbed. However, with increased investment in technology, science and technology funding has not played a sufficient role in the production factors. Enterprises and regions only use funds to blindly introduce equipment and technology without comprehensively considering their own technical conditions, leading to idleness of the equipment and unsatisfactory quantity and quality of innovation output. These are due to the unreasonable allocation of innovation resources, causing a waste of resources and leading to the decline of green innovation efficiency, many scholars have reached the same conclusion [47-48].

\section{Conclusions}

This study used panel data from 30 provinces in mainland China from 2007 to 2019. Based on measuring the green innovation efficiency in each region, we constructed a measurement model to empirically test the effect of environmental regulations on green innovation efficiency. The empirical analysis results show that during the period under review, China's green innovation efficiency was lower than the traditional efficiency without considering undesired output; as a comparison, the eastern region, with a relatively developed economy, had higher green innovation efficiency, while the central and western regions had higher efficiency. The average green innovation efficiency was lower than the national average. Therefore, for the central and western regions, on the one hand, efforts should be made to improve the enthusiasm of R\&D personnel for innovation and the efficiency of the use of R\&D funds to promote the improvement of green innovation levels through institutional changes and management innovation. On the other hand, actively promoting the construction of green innovation projects in this region while enhancing the capacity of independent green innovation will strengthen the ability to undertake green technology transfer in the eastern region and to absorb advanced foreign technology. In the future, the eastern region should further promote the construction of green innovation, improve its efficiency, and properly guide the flow of resources to the central and western regions while maintaining its innovation advantages.

There is a U-shaped relationship between environmental regulation and corporate green innovation efficiency, indicating that as the intensity of environmental regulation increases, its impact on green innovation efficiency will increase. From the 
suppression effect to the innovation effect, there is an inflection point in the intensity of environmental regulation across which its promotion effect on green innovation can be played. Therefore, formulating appropriate environmental regulatory policies is conducive to the effective development of green innovation activities in various regions, and is also beneficial for the health and sustainable development of the economy. At the same time, the government needs to adopt different environmental regulation measures based on the level of green innovation development and the degree of environmental pollution in different regions. For the eastern region, the role of environmental regulation in promoting green innovation efficiency should be extended based on appropriately increasing its intensity; at the same time, we must further strengthen research and development, select more efficient production processes, and focus on innovation, energy saving, and emission reduction in the production process, further improving the efficiency of green innovation. The central and western regions need to focus on strengthening the construction of green innovation systems based on strengthening the implementation of regulations and improving their effects, improving infrastructure construction as soon as possible, and developing appropriate talent training and introduction mechanisms to improve the weak local green innovation foundation and the lack of innovative talent and improve the status of green innovation.

\section{Limitations and Prospect}

There are also deficiencies in this paper: (1) This study uses data of national regions to provide a reference for the relevant regions of China, which also causes a problem of large research scope. It is not possible to study the problems of a specific region in detail. (2) This study uses the DEA model to measure the efficiency of green innovation, based on which the system GMM model is used to verify the influencing factors. Although the estimation results are well explained, the spatial effects of variables were not considered. Further research will continue to take into account the influence of space effects.

The paper will introduce spatial factors in future research, because the changes in green innovation efficiency may have spatial spillover effects, so the existence of spatial effects cannot be ignored. Therefore, spatial measurement analysis methods can be used to study the effect of environmental regulations on regional green innovation efficiency. Compared with the research in this article, we can draw more meaningful conclusions. At the same time, we can also consider the impact of different types of environmental regulations on the efficiency of green innovation, and supplement and improve existing research.

\section{Acknowledgements}

This work was supported by National Natural Science Foundation of China (7118330064); General Program of Humanities and Social Sciences Research of the Ministry of Education (18YJA790085).

\section{Conflict of Interest}

The authors declare no conflict of interest.

\section{References}

1. YANG J.J., LIU Y.F., LI H.L. Trade facilitation, intermediate goods import and enterprise export value added. Finance and Trade Economics, (4), 115, 2020.

2. GUO R., LU S., CAO X.J., WANG X. Research on the allocation efficiency of carbon emission reduction in China's six major industries based on the ZSG-DEA model. Ecological Economy, (1), 13, 2020.

3. WEN Z.C., LI J.F., ZHU B.L. Research on China's long-term consumption development trend and energy environmental effects. China Environmental Management, 12 (1), 43, 2020.

4. WANG.R., Zameer H., FENG Y., JIAO Z.L., XU L., GEDIKLI A.Revisiting Chinese Resource Curse Hypothesis Based on Spatial Spillover Effect: A Fresh Evidence. Resources Policy, (64), Article No. 101521, 2019.

5. NASIEROWSKI W., ARCELUS F.J. About Efficiency of Innovations: What Can Be Learned From the Innovation Union Scoreboard Index-Procedia-Social and Behavioral Sciences, $\mathbf{5 8}$ ( 58), 792,2012

6. REN Y., NIU C.H., NIU T. Theoretical Model and Empirical Study of Green Innovation Efficiency. Management World, (7), 176, 2014.

7. LIU M.G. Study on the Spatial Distribution and Convergence of Green Innovation Efficiency of Regional Innovation System. Industrial Technology and Economy, (4), 10, 2017.

8. GAO G.W., WANG Y.Q. Analysis of Green Innovation Efficiency and Influencing Factors of High Energy Consumption Industries in Beijing-Tianjin-Hebei Region - An Empirical Study Based on a Space Perspective. Industrial Technology and Economy, (1), 137, 2018.

9. ZHANG W., LI H.L., AN X.B. Exploring the theoretical model and thinking of using FDI to enhance China's green innovation capability. Management World, (12), 170, 2011.

10. YIN Q., CHENG Y. Study on the Regional Differences and Causes of China's Green Innovation Efficiency. Jiangsu Social Sciences, (2), 64,2016.

11. FENG Z.J. Research on Green Innovation Efficiency of Chinese Industrial Enterprises. China Science and Technology Forum, (2), 82, 2013.

12. YAO X.L., NIU C.H., LIU J. Research on Innovation Drive, Green Development and the Transition Efficiency of China's Industrial Economy. China Science and Technology Forum, (1), 57, 2015.

13. NIU T., PENG S.Y., NIU C.H.Research on Green Innovation Efficiency of Industrial Enterprises in Shanxi Province Based on SBM-DEA Four-phase Method. 
Science and Technology Management Research, (10), 244, 2015.

14. WU M.Q., XIAO H., FAN X.H. Study on the Efficiency of Regional Green Innovation in Three Stages Analysis Based on NSBM Model. Journal of Shanxi University (Philosophy and Social Science Edition), (6), 79, 2016

15. LI J.Z., LI Z.Y., LI C. Empirical Research on Urban Green Innovation Efficiency - Evidence from Urban Agglomeration in the Middle Reaches of the Yangtze River. Journal of Jiangxi University of Finance and Economics, (6), 3, 2016.

16. WANG C.X., REN Y.J. Spatial spillover effects of green innovation efficiency in high-tech industries. Sankei Review, (6), 76, 2016.

17. HAN J. Study on Regional Green Innovation Efficiency in China. Research on Financial and Economic Issues, (11), 130, 2012.

18. PORTER M.E., VAN D.L.C. Toward a New Conception of the Environment-Competitiveness Relationship. The Journal of Economic Perspectives, 9 ( 4), 97, 1995.

19. ZHANG J., GENG H., XU G.W. Research on the Impact of Environmental Regulations on Green Technology Innovation. China Population, Resources and Environment, (1), 168, 2019.

20. XU H., LI G.Y. Research on the Impact of Environmental Regulation on the Efficiency of Green Innovation. Research on Financial and Economic Issues, (9), 52, 2018.

21. YANG S.W., WU T., LI Z.B. Study on the Spatiotemporal Differentiation of Green Innovation Efficiency and Its Influencing Factors in the Yangtze River Economic Belt. Macroeconomic Research, (6), 107, 2018.

22. WANG Y., LI J.M. The main methods, potential problems and their amendments for measuring the intensity of environmental regulations. Economics and Trade Forum, (5), 98, 2015

23. XIANG X.D., LIN J. Research on the Evaluation of Total Factor Productivity of Chinese Industry under Environmental Regulations: Based on the Global Network DEA-Malmquist Index. Science and Technology Management Research, (6), 60, 2018.

24. PENG W.B., CHENG F.F., LU J.L. Study on the Threshold Effect of Environmental Regulations on Provincial Green Innovation Efficiency. Southern Economy, (9), 73, 2017.

25. HORBACH J. Empirical determinants of eco-innovation in European countries using the community innovation survey. Environmental Innovation \& Societal Transitions, 19 (4), 1, 2015.

26. CHEN W. Analysis of Environmental Regulation Tools for SMEs Based on Tradable Pollution Emission Permits. Southern Economy, 29 (10), 58, 2011.

27. YOU J.H, WANG P. Can Environmental Regulations Promote R \& D Preference to Green Technology R \& D? An Empirical Study Based on Chinese Industrial Sectors. Economic Review, (3), 26, 2016

28. TONE K., TSUTSUI M. Network DEA: A Slacks-Based Measure Approach.European Journal of Operational Research, (1), $243,2009$.

29. HANSEN B.E. Threshold Effects in Non-Dynamic Panels: Estimation, Testing, and Inference [J]. Journal of Econometrics, 93 (2), 345, 1999.

30. ANTWEILER W., COPELAND B.R., TAYLOR M.S. Is Free Trade Good for the Environment. American Economic Re-view, 91 (4), 877, 2001.
31. MANI W. In Search of Pollution Havens? Dirty Industry in the World Economy, 1960-1995. Journal of Environment and Development, 7 (3), 215, 1998.

32. COLE M.A, ELLIOTT R.J.R. Determining the Tradeenvironment Composition Effect: The Role of Capital, Labor and Environment Regulations. Journal of Environmental E-conomics and Management, (46), 363, 2003.

33. DOMAZLICKY B.R., WEBER W.L. Does Environmental Protection Lead to Slower Productivity Growth in the Chemical Industry. Environmental and Resource Economics, 28 (3), 301, 2004.

34. LANOIE P., PARTY M., LAJEUNESSE R. Environment Regulation and Productivity: Testing the Porter Hypothesis. Journal of Productivity Analysis, 30 (2), 121, 2008.

35. SHEN N. Environmental Efficiency, Industry Heterogeneity, and Optimal Regulatory Strength: Nonlinear Tests of Panel Data for China's Industrial Industries. China Industrial Economy, (3), 56,2012.

36. WANG J., LIU B. Environmental Regulation and Enterprise Total Factor Productivity - A Test and Analysis Based on the Data of Chinese Industrial Enterprises. China Industrial Economy, (3), 44, 2014.

37. LIN S.F., SUN J., MARINOVA D.,ZHAO D.T. Evaluation of the green technology innovation efficiency of China's manufacturing industries: DEA window analysis with ideal window width. Technology Analysis \& Strategic Management, 30 (10), 1166, 2018

38. GAO Y., TSAI S.B., XUE X.Q., REN T.Z., DU X.M., CHEN Q., WANG J.T. An Empirical Study on Green Innovation Efficiency in the Green Institutional Environment. Sustainability, 10 (3), 724, 2018.

39. FENG Z.J., ZENG B.,MING Q. Environmental Regulation, Two-Way Foreign Direct Investment, and Green Innovation Efficiency in China's Manufacturing Industry. International Journal of Environmental Research and Public Health, 15 (10), 2292, 2018.

40. LI H., HE F., DENG G. How does Environmental Regulation Promote Technological Innovation and Green Development? New Evidence from China. Polish Journal of Environmental Studies, 29 (1), 689,2020.

41. GAO P., WANG X.H. Financial investment, environmental regulation and green technology innovation efficiency: Empirical evidence based on the data of industrial enterprises above designated size from 2008 to 2015. Ecological Economy, (4), 93, 2018.

42. HOU Y.Q., WANG F.Y. Research on the dynamic relationship between green innovation and economic growth - an empirical analysis based on VAR model. Ecological Economy, (5), 44, 2020.

43. XIAO Y.F., WU Y. FDI, environmental regulation policies and regional green innovation efficiency. Journal of Chongqing University of Technology (Social Sciences), 33 (6), 50, 2019.

44. LIU B.B., HUANG J.Y. Research on the Impact of FDI Entry Mode on Regional Green Technology Innovation Efficiency - Based on the Perspective of the Difference in Environmental Regulation Intensity. Contemporary Finance, (4), 89, 2017.

45. LUO Y., CHEN P. Research on the Threshold Effect of Environmental Regulation on the Improvement of China's Industrial Green Innovation Efficiency. Journal of Northeastern University (Social Science Edition), 20 (02), 147,2018

46. JIANG X., SHEN J.Y., ZHANG D.Y. Research on the impact of human capital on the innovation performance 
of the green innovation system - Based on the DEA-Tobit analysis of China's manufacturing industry. Technology and Management, 21 (02), 23, 2019 .

47. WANG Y.H. Sichuan: Innovating Fiscal Policy Mechanism and Vigorously Promoting Green Development. China Finance, (20), 35, 2017.
48. ZHANG L. Environmental regulation, green technology innovation and manufacturing transformation and upgrading path. Taxation and Economy, (1), 51, 2020. 
